Selcuk Journal of Agriculture and Food Sciences

http://sjafs.selcuk.edu.tr/sjafs/index

Research Article
SJAFS

(2021) 35 (2), 155-160

e-ISSN: 2458-8377

DOI:10.15316/SJAFS.2021.243

\title{
Evaluation of Plant Distribution Regularity in Sowing with Different Guidance Systems by GPS, GIS and Voronoi Polygons
}

\author{
iD Nurettin KAYAHAN ${ }^{1, *}$, ID Taner ÜSTÜNTAŞ ${ }^{2}$ \\ ${ }^{1}$ Selçuk University, Faculty of Agriculture, Department of Agricultural Machineries and Tecnologies Engineering, \\ Konya, Turkey \\ ${ }^{2}$ Kocaeli University, Faculty of Engineering, Department of Geomatics Engineering, Kocaeli, Turkey
}

\begin{tabular}{l}
\hline ARTICLE INFO \\
\hline Article history: \\
Received date: 01.07 .2021 \\
Accepted date: 12.07 .2021 \\
\hline
\end{tabular}

Keywords:

RTK

Voronoi

CBS

GPS

\begin{abstract}
In this study, sowing was carried out with 3 different tractor guidance methods: operator-controled, GPS-controled and automatic-controled. The optimum nutrient areas required for each plant were evaluated using voronoi polygons. Voronoi polygons were used to obtain nutrient areas. Voronoi polygons were used to obtain living spaces. The plant coordinates taken with CORS-RTK GPS were loaded into the CBS program and the voronoi polygon for each plant was obtained. Comparison of nutrient areas was made with shape coefficients calculated using polygon area and perimeter values. Shape coefficient was 0.731 in operator-controlled application, 0.746 in GPS-controlled application and 0.715 in automatic-controled application. Compared to operator-controlled application, shape coefficients were found to be $2 \%$ more in GPS-controlled application and $2 \%$ less in automatic-controlled application. Although the shape coefficients are relatively less in the automatic-controlled system, it can be seen that better results can be obtained in terms of field success due to the advantages such as low workload on the operator, ease of application at night and improvements in time utilization coefficient. As a result of the statistical analysis, it has been found that there is no difference between the applications and can be used interchangeably. As a result, when the systems are compared with each other, it is seen that the automatic-controlled application is more successful.
\end{abstract}

\section{Introduction}

The main purpose of the sowing process is to place the seeds in a horizontal and vertical position in order to provide optimal conditions for germination, growth, inter-row processing and harvest (Páltik et al. 2005).

In addition to the use of good seeds in a quality sowing process, deciding on the right sowing method, choosing the right machine and correct application provides an increase in yield and reduces the cost by reducing unnecessary processes (Yazg1 et al. 2012).

It has been observed that the development of agricultural products can be improved by regulating the spatial distribution of the plants (Andrade and Abbate 2005; Weiner et al. 2001).

In many studies, it is seen that the uniformity of sowing is determined by using only the inter-row distances. However, the main effective factor on yield

\footnotetext{
* Corresponding author email: nkayahan@selcuk.edu.tr This study is summarized from the Ph.D Thesis of Nurettin KAYAHAN supported by BAP Coordinatorship of Selçuk University, Konya, Turkey (Project No. 18101005).
}

and plant growth is the plant nutrient areas, and this should be examined in two dimensions (Karayel 2010; Karayel and Özmerzi 2010).

The quality of the horizontal and vertical distribution of seeds is affected by the distance between rows, sowing depth, soil condition, planter design, seed density and operator skill (Griepentrog 1998).

Better seed distribution mainly provides three main benefits: better yield and quality, better weed competition, more effective physical weed control and chemical application (Griepentrog and Blackmore 2007).

Computational geometry, which emerged as a research branch and can be tried relatively recently in other theoretical fields, finds many application areas in today's world. For example, the creation of digital terrain models, finding the shortest (not passing through obstacles) path between two points on a map, and calculating areas that represent points in a field are some of the most important problems that can be counted in this field (Karayel 2010).

While doing the delaunay triangulation, which is included in the computational geometry, "the segment 
of the line connecting each point with the point closest to it" forms a triangle side. (Figure 1). The triangles formed are the most likely equilateral triangles (equiangularity feature).

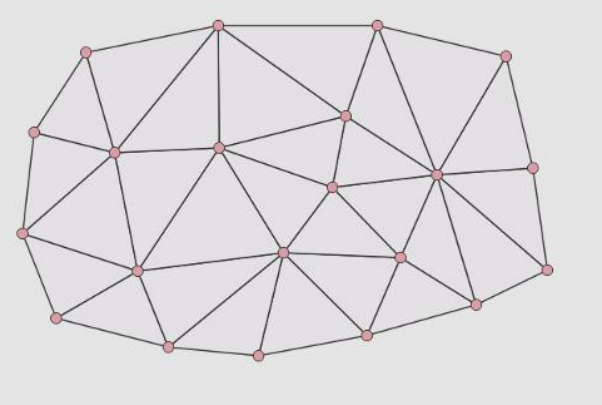

Figure 1

Delaunay triangulation

The voronoi polygon of a point separates any point from neighboring points closest to it. As seen in Figure 2 , the edges of the polygon consist of the side center posts of the line segments connecting the point and the neighboring points (Yanalak 2001).

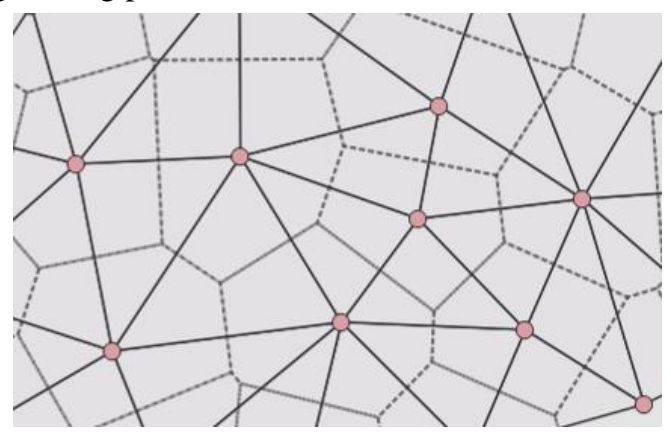

Figure 2

Veroni polygons

The aim of this study is to evaluate the plant distribution uniformity in terms of nutrient area by using GPS and GIS computational geometry by sowing maize with operator-controlled, GPS-controlled and domestic automatic-controlled guidance system.

\section{Materials and Methods}

This study was carried out in Selçuk University Faculty of Agriculture Saricalar Research and Application Farm in Konya province. In the study, 12 parcels of $100 \mathrm{~m}$ length and $2.8 \mathrm{~m}$ width were used for maize cultivation. In order to prepare a seed bed in the field, a vertical shaft rototiller with a toothed roller is used.

In the research, four rows and tractor mounted vacuum type pneumatic precision seed drill driven from the PTO was used. Seed discs with a hole diameter of $4.5 \mathrm{~mm}$ were used in the experiment. The seed spacing between the rows of the machine is $70 \mathrm{~cm}$ and the seed spacing along the row is set to $16 \mathrm{~cm}$. The hoeing process was carried out with a interrow hoe machine and irrigation and fertilization was done with the drip irrigation system.
GPS-controlled sowing was done with the domestic guidance system of Agrisign company and Automaticcontrolled sowing was done with the prototype control system integrated into the same system. The system consists of a laptop with GPS and automatic control software, CORS-RTK GPS antenna, rubber wedge servo motor, motor driver, wheel protractor, etc. additional equipment.

The system is mounted on the NEW HOLLAND brand TD 110 model tractor to be used in sowing In order to adapt the system to the tractor, the sheet material, which was drawn in the Solidworks program before and which has mounting holes on it to be fixed to the screw places on the tractor steering wheel, was cut on the laser bench and attached to the tractor. The steering wheel is moved by a servo motor that connects a rubber wedge to the shaft on the system, and this servo motor is placed in the plastic sleeve drawn in Solidworks program and then created with a $3 \mathrm{D}$ printer. The engine sleeve is attached to the sheet metal part mounted on the steering wheel, hinged and springloaded so that it can be separated from the steering wheel if desired. The general view of the system on the tractor is given in Figure 3.

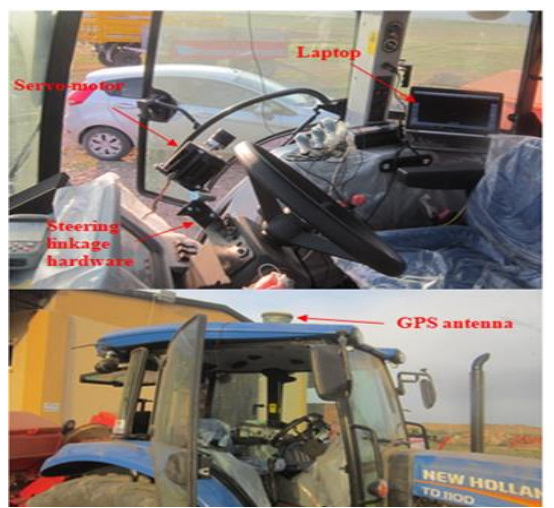

Figure 3

General view of GPS and automatic control system

The steering system is set to move straight on the AB line before operation. The height of the GPS antenna, the hanging type of the equipment connected to the tractor, the working width and length of the connected equipment, the distance from the tractor and the distance from the GPS have been entered into the system beforehand. In GPS guided sowing, the servo motor is separated from the steering wheel and the operator uses the steering wheel by moving it to the right or left according to the directions on the program screen. In automatic mode, the servo motor is connected to the steering wheel and steering is made by the system automatically turning the steering wheel.

In the study, SATLAB brand SL 500 model GPS, handheld terminal and topcon brand carbon fiber pole working according to the CORS-RTK principle were used to determine the coordinates of the plants.

Satlab GNSS Office Software and Google Earth software were used to make the appropriate transformations of the location data obtained by GPS. 
Viewing and processing the location data taken from plants, creating voronoi polygons, calculating their areas and perimeters were done with the QGIS GIS program.

A standard Asus laptop computer with Intel Core i5 $2.4 \mathrm{GHz}$ processor, $4 \mathrm{~GB}$ memory and $320 \mathrm{~GB}$ hard drive was used for running the programs and other data analysis. Statistical analyzer was done in Minitab program. Tape measure, digital caliper and charge balance were used in the measurements taken from the plants during the harvest.

Before sowing in the field, the seed bed was prepared with a vertical axis rotary tiller. The intrarow distance of the seeder, whose interrow distance is 70 $\mathrm{cm}$, is set as $16 \mathrm{~cm}$. The fertilizer norm of the seeder has been adjusted to be $40 \mathrm{~kg}$ DAP per decare.

On May 16, 2018, sowing was carried out with 4 replications according to the randomized blocks trial order with 3 different methods: operator-controlled, GPS-controlled and automatic-controlled.

Irrigation was done with drip irrigation and during cultivation, a total of $496 \mathrm{~mm}$ of water was given. During the cultivation, 1 time hoe and 1 time weed spraying was done. Top fertilizer was given by drip irrigation in the form of urea, in total $40 \mathrm{~kg}$ per decare after the hoe application. Mustang was used as a herbicide with $70 \mathrm{ml}$ per decare. The maize in the plots reached harvest maturity on September 19, 2018, and harvest measurements were made on yield and quality characteristics on this date.

In order to determine the seed distribution uniformity of the plants, the nutrient area-based method consisting of the voronoi polygon of each plant was used. Theoretically, the ideal nutrient area of a plant is the circle. The shape coefficient was used to determine how close the created nutrient areas are to the ideal nutrient area, geometrically (Griepentrog 1998). The fact that the shape coefficient approaches 1 indicates that the nutrient area also approaches the circular shape at the same rate. The shape coefficient is the ratio of the circumference of the circle surrounding

Table 1

Measurements taken from plants during harvest in field

\begin{tabular}{lcccccccccc}
\hline Aplication & $\begin{array}{c}\text { Plant } \\
\text { height } \\
(\mathrm{cm})\end{array}$ & $\begin{array}{c}\text { Number } \\
\text { of cob } \\
(\text { piece })\end{array}$ & $\begin{array}{c}\text { Height } \\
\text { of cob } \\
(\mathrm{cm})\end{array}$ & $\begin{array}{c}\text { Stem } \\
\text { diameter } \\
(\mathrm{mm})\end{array}$ & $\begin{array}{c}\text { Leaf } \\
\text { length } \\
(\mathrm{cm})\end{array}$ & $\begin{array}{c}\text { Leaf } \\
\text { width } \\
(\mathrm{cm})\end{array}$ & $\begin{array}{c}\text { Plant } \\
\text { weight } \\
(\mathrm{g})\end{array}$ & $\begin{array}{c}\text { Leaf } \\
\text { weight } \\
(\mathrm{g})\end{array}$ & $\begin{array}{c}\text { Cob } \\
\text { weight } \\
(\mathrm{g})\end{array}$ & $\begin{array}{c}\text { Stem } \\
\text { weight } \\
(\mathrm{g})\end{array}$ \\
\hline $\begin{array}{l}\text { Operator- } \\
\text { controlled }\end{array}$ & 258,03 & 1 & 89,18 & 24,99 & 93,05 & 9,88 & 833,73 & 136,48 & 270,53 & 426,73 \\
$\begin{array}{l}\text { GPS- } \\
\begin{array}{l}\text { Controlled } \\
\text { Automatic- }\end{array}\end{array}$ & 252,28 & 1 & 88,28 & 25,22 & 90,95 & 9,76 & 822,43 & 131,50 & 267,68 & 423,25 \\
Controlled & 249,45 & 1 & 95,48 & 24,10 & 94,08 & 9,85 & 820,30 & 137,40 & 263,10 & 419,80 \\
\hline
\end{tabular}

The images of the voronoi polygons obtained from all the plots where the sowings were made with the operator-controled, GPS-controled and automatic- the ideal living area to the perimeter of the polygon calculated as the plant's nutrient area.

The coordinates of the plants in the $2 \mathrm{~m}$ section of each plot (4 rows) were measured with a high-accuracy CORS-RTK GPS device in order to determine the nutrient areas after the seedling emergence. The coordinates of the plants recorded by the GPS device were loaded into the QGIS GIS program after the appropriate transformations were made in Satlab GNSS Office and Google Earth Pro programs. By choosing the voronoi command in the QGIS GIS program, the voronoi polygons of each plant were calculated. Among these polygons, 20 polygons belonging to the middle rows for each parcel were selected to calculate their areas and perimeters. By entering the attribute table of the file containing the selected polygons, the polygon area and its perimeters are added to the attribute table with the option to create a new area option. After obtaining the area and perimeter of the polygons, the files of the polygons were saved in $\mathrm{dbf}$ format, which could be opened by the Excel program and the values in the attribute table could be seen from the save as menu. These files were opened in the Excel program and the ideal circle radius, circumference and shape coefficient values for each living area were calculated. The obtained shape coefficients were subjected to analysis of variance using Minitab program.

Plant height, number of cobs, height of cobs, stem diameter, leaf length, leaf width, plant weight, leaf weight, cob weight and stem weight were measured in 20 plants determined from each plot during the harvest.

\section{Results and Discussion}

Plant height, number of cobs, height of cobs, stem diameter, leaf length, leaf width, plant weight, leaf weight, cob weight and stem weight were measured during harvesting and the average of the repeated measurements was calculated. The results of these measurements are given in Table 1. controled guidance systems obtained in the QGIS GIS program are given in Figure 4, Figure 5 and Figure 6. 
Kayahan and Üstüntaş / Selcuk J Agr Food Sci, (2021) 35 (2): 155-160

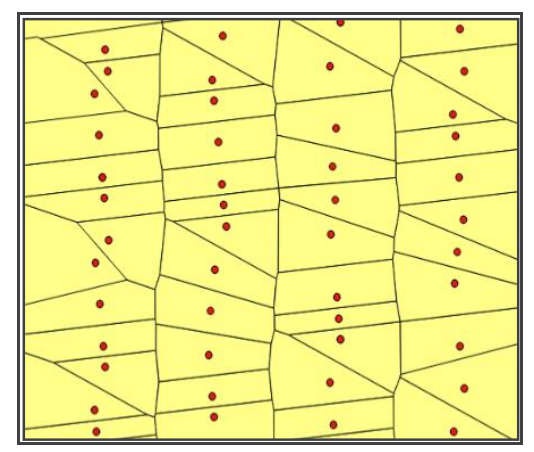

A

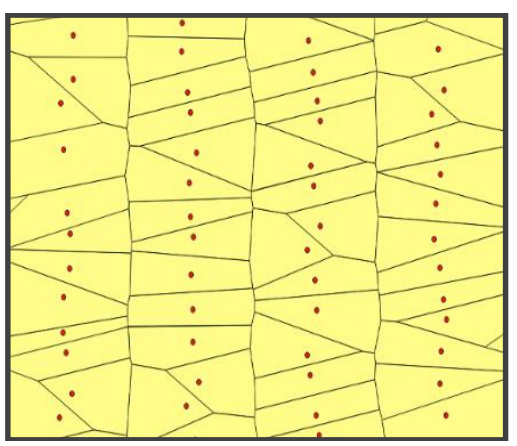

C

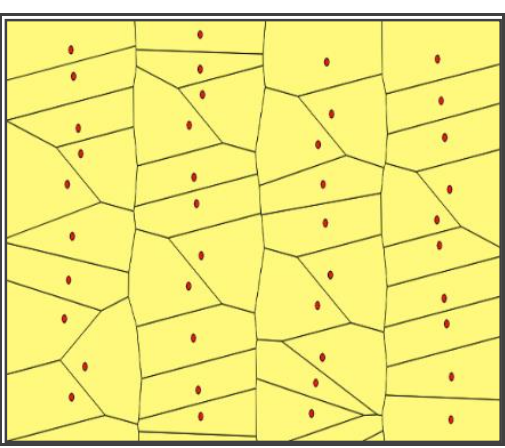

B

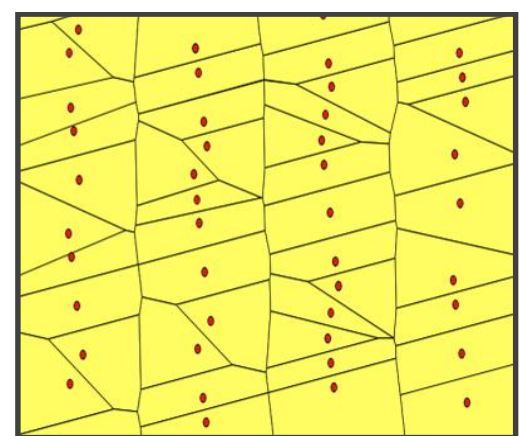

D

Figure 4

Veroni polygons of plant nutrient areas in operator-controlled application (A: 1st replication, B: 2nd replication, C: 3rd replication D: 4th replication)

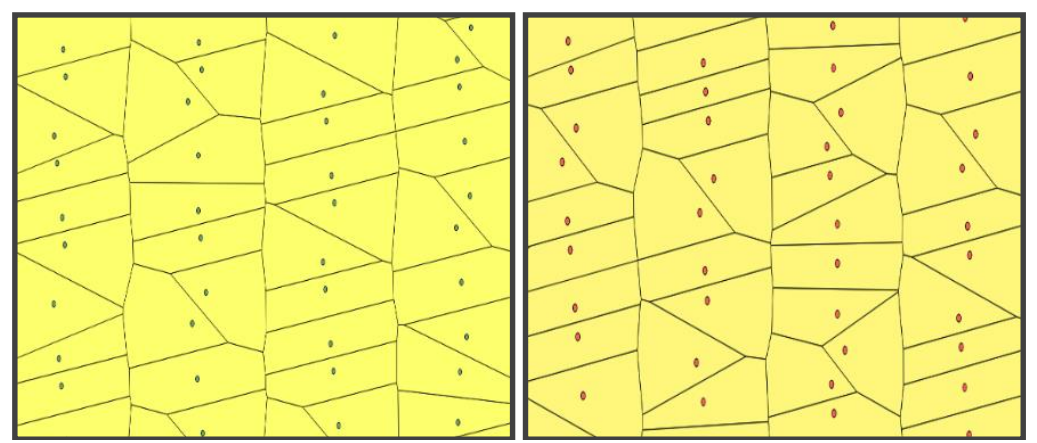

A

B

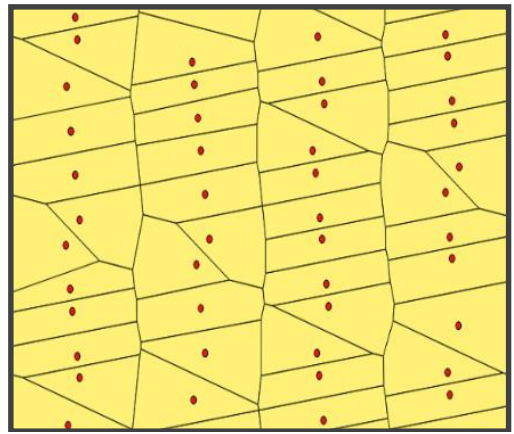

C

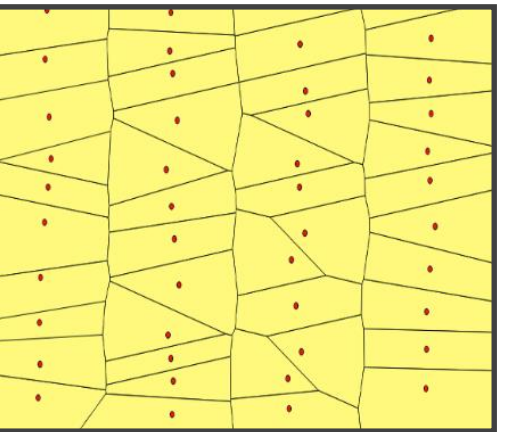

D

Figure 5

Veroni polygons of plant nutrient areas in GPS-controlled application (A: 1st replication, B: 2nd replication, C: 3rd replication D: 4th replication) 


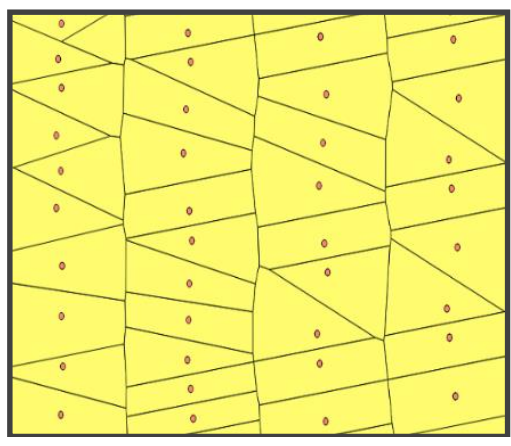

A

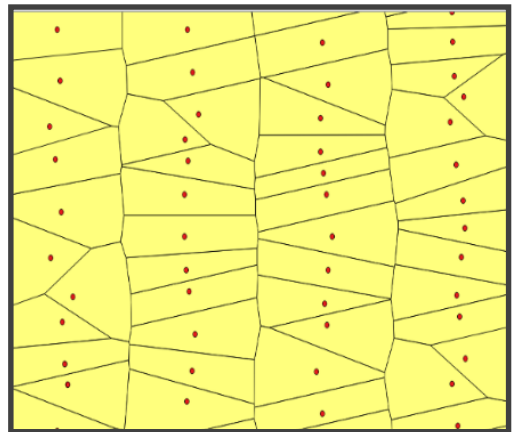

C

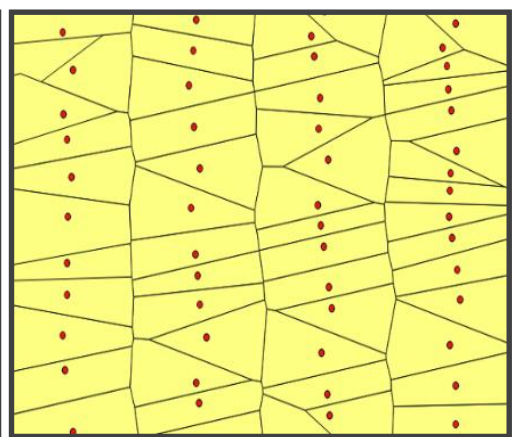

B

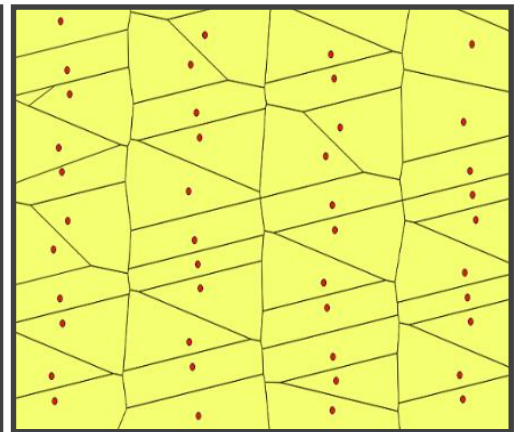

D

Figure 6

Veroni polygons of plant nutrient areas in automatic-controlled application (A: 1st replication, B: 2nd replication, C: 3rd replication D: 4th replication)

Shape coefficient values of application replications and averages are given in Table 2, and average shape coefficients are presented graphically in Figure 7.

Table 2

Shape coefficients of replications and averages

\begin{tabular}{lcc}
\hline Method & Replication & Shape coefficient \\
\hline \multirow{3}{*}{ Operator-controlled } & 1 & 0,727 \\
& 2 & 0,751 \\
Average & 3 & 0,730 \\
& 4 & 0,715 \\
GPS-controlled & 1 & 0,731 \\
& 2 & 0,761 \\
Average & 3 & 0,744 \\
& 4 & 0,739 \\
Automatic-controlled & & 0,738 \\
& 1 & 0,746 \\
Average & 2 & 0,693 \\
& 3 & 0,723 \\
& 4 & 0,711 \\
& & 0,731 \\
\end{tabular}

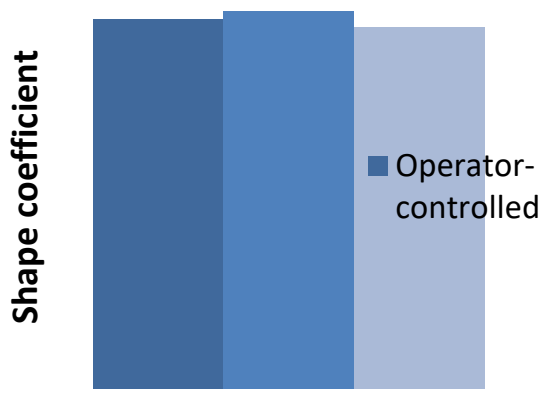

Figure 7

Average shape coefficients
When Table 2 and Figure 7 are examined, it is seen that the shape coefficient values vary between 0.693 and 0.761 . The highest shape coefficient value was obtained in the 1 st replication of the GPS-controlled application, and the lowest shape coefficient value was obtained in the 1 st replication of the automatically controlled application. Considering the average values of the applications, the highest shape coefficient was obtained in the GPS-controlled application, and the lowest shape coefficient was obtained in the automatic controlled application. Compared to the operatorcontrolled application, the shape coefficient was found to be $2 \%$ higher in the GPS-controlled application and $2 \%$ less in the automatic-controlled application.

The obtained shape coefficients were subjected to logarithmic transformation before being subjected to analysis of variance. Normality test was performed according to the Shapiro-Wilk statistical method in order to understand whether the analysis of variance satisfies the assumption of normality. As a result of the test, P-Value values were greater than 0.05 for all applications and it was determined that the data showed a normal distribution. In addition, Bartlett and Levene tests were performed to understand whether the values showed a homogeneous distribution. As a result of the test, P-Value values of Bartlett and Levene tests for all applications were found to be greater than 0.05 and it was determined that the values showed a homogeneous distribution.

When the results of the statistical analysis of variance are examined, it is understood that the difference between the operator, GPS, and automatic 
controlled guidance applications is insignificant according to the statistical significance level of $5 \%$.

When the literature is examined, there are very limited studies on the examination of seed distribution uniformity based on the determination of voronoi polygons and nutrient areas. When the existing studies (Karayel 2010; Karayel et al. 2012; Griepentrog 1998; NZI et al. 2017) are examined, it is seen that the obtained shape coefficient values have similar results with these studies.

Although the shape coefficient is found to be $2 \%$ less in the automatic controlled guidance application compared to the operator controlled guidance application, this difference is insignificant as seen in the statistical analysis. Therefore, automatic controlled guidance application is more advantageous due to its advantages such as less load on the operator and better utilization of time.

In this study, maize was sown in the field using the randomized blocks experimental scheme with operatorcontrolled, GPS-controlled and automatic-controlled guidance systems, and sowing evenness was evaluated in terms of shape coefficients calculated using nutrient areas. Theoretically, the ideal living space is the circle. The shape coefficient of the circle is 1 , and the value of the shape coefficient of the living areas approaching 1 is an indicator of how close it is to the circle.

As a result of this study, in which operator, GPS and automatic controlled guidance were used, it was determined that the difference between all applications was statistically insignificant at the $5 \%$ significance level.

In operator-controlled guidance, there may be more fatigue and a decrease in efficiency because the operator will have more workload. GPS and automatically controlled guidance systems reduce the workload on the operator and provide a more effective working opportunity.

GPS and automatically controlled routing systems can also increase the time utilization coefficient by reducing the operator load.

The use of GPS and automatically controlled guidance systems can enable sensitive field applications that are difficult to be made at night, as well as at night.

\section{Acknowledgements}

This research was supported by BAP Coordinatorship of Selçuk University, Konya, Turkey (Project No.
18101005). The authors would like to acknowledge the financial support of BAP Coordinatorship of Selçuk University and to thank the decedent Prof. Dr. Cevat AYDIN who has contributed to this research.

\section{References}

Andrade FH, Abbate PE (2005). Response of maize and soybean to variability in stand uniformity. Agronomy Journal 97 (4): 1263-1269.

Griepentrog HW (1998). Seed distribution over the area, International Conference on Agricultural Engineering: AgEng, Oslo, 1998, 663-664.

Griepentrog HW, Blackmore BS (2007). Autonomous crop establishment and control systems. In Ikke angivet VDI Verlag GmbH.

Karayel D (2010). Evaluation of seed distribution in the horizontal plane and plant growing area for row seeding using voronoi polygons. Journal of Agricultural Sciences 16: 97-103. (in Turkish)

Karayel D, Özmerzi A (2010). Ekim makinalarının tohum dağılımının incelenmesinde yeni yaklaşımlar: Iki boyutlu değerlendirme. Tarım Makinaları Bilimi Dergisi 6(2): 101-106.

Karayel D, Topakci M, Unal I, ŠARAUSKIS E, Canakci M (2012). Using real-time kinematic (RTK) global positioning system (GPS) for the determination of seedling distributions over the field, Žemdirbystè. Akademija,(Kédainiu r.) T. 99, Nr. 4

Nzi DVP, Kayahan N, Çarman K (2017). Determination of surface seed distribution in the different seeding methods of maize. Selcuk Journal of Agriculture and Food Sciences 31(1): 48-55.

Páltik J, Nozdrovický L, Findura P, Maga J (2005) Quality of the seed placing in seeding of sugar beet. Research in Agriculturalo Engineering (1): 33-38.

Weiner J, Griepentrog HW, Kristensen L (2001). Suppression of weeds by spring wheat Triticum aestivum increases with crop density and spatial uniformity. Journal of Applied Ecology 38(4): 784790.

Yanalak M (2001). Triangulation Methods in Surface Modelling. Map Journal, 126, 58-69. (in Turkish)

Yazgi A, Dumanoğlu Z, Kuldemir N, Aygün İD Masoumi A (2012). Determination of the machine performance for wheat seeding by pneumatic seed drill. Journal of Agricultural Machinery Science 8 (1): 35-40. 